\title{
Prof. Dr. rer. nat. Hans Schaefer
}

Hans Schaefer was born on November 15, 1935 in Duisburg to a family of merchants. We are paying tribute to him on the occasion of his 65th birthday for his contributions via the natural sciences, and especially biochemistry, to the development of dermatology and its integration into the functional approach to medicine.

Traditionally, research laboratories of dermatological university clinics had their own chemist. Eventually, awareness grew that a biochemist, based on his or her experience and intuition of pathophysiological phenomena and their clarification, could contribution own conceptions that could find clinical applications. Hans Schaefer's work is an example for the integration of research in the natural sciences and its practical implementation in clinical thinking and practice.

$\mathrm{He}$ started his studies of chemistry at the University of Bonn in 1955, extenting them by a 6-month stay at the Istitutio Superiore di Sanità in Rome and concluding them with his doctoral thesis on the "Metabolism and Toxicology of Fluoro-Acetic Acid' in 1965. That same year, he accepted the offer to run Thomae/Boehringer's Dermatological Research Laboratory. He succeeded in developing a number of new methods, especially for deter-

\begin{tabular}{ll}
\hline KARGER & @ 2000 S. Karger AG, Basel \\
Fax +4161306 12 34 & 1422-2868/00/0136-0297\$17.50/0 \\
$\begin{array}{l}\text { E-Mail karger@karger.ch } \\
\text { www.karger.com }\end{array}$ & $\begin{array}{l}\text { Accessible online at: } \\
\text { www.karger.com/journals/sph }\end{array}$
\end{tabular}

mining levels of sebaceous matter differentiating serum lipids from epidermal lipids. The chemical data of the surface of the skin were correlated with reactions to physical stimuli.

Schaefer's interest in clinical phenomena did not remain unnoticed and, in 1969, led to an offer from Rudolf Virchow Hospital, University Dermatological Clinic in Berlin, to become the head of a dermatological research laboratory with emphasis on biochemistry. There he helped in designing the translation of clinical pharmacology into functional dermatology, which was initiated in that clinic. In 1971, he received the Oscar Gans Award for a new method for the quantitative determination of sebum excretion. In that same year, he was awarded the 'venia legendi' for biochemistry in dermatology at the Free University of Berlin. His habilitation thesis, 'Investigation on Biochemical Turnover Parameters in Living Tissue', presented a technically ingenious method for the continuous measurement of intracellular and intercellular processes of the skin in living cells in vivo and in vitro. This led to the development of an apparatus which allows the differentiation of enzymatic conversions in cells from processes caused by enzymes diffusing from tissue. This

Dr. Günter Stüttgen

Em. o. Professor of Dermatology and Venerology of the

Free University of Berlin, Kissinger Strasse 12

D-14199 Berlin (Germany)

Tel./Fax +49 308239661 
procedure involves uncovering the superficial living cell layers of the epidermis using adhesive tape, which allows the enzymatic analysis of a total volume of $0.2 \mathrm{ml}$ after application of glass capsules. It also led to the direct determination of the effects of systemic administration of drugs, such as corticosteroids or methotrexate, on the cellular metabolism of the skin. In 1972, the free University of Berlin appointed Hans Schaefer university professor. In the following years, in vitro and in vivo methods for measuring the permeation of drugs under standard conditions were in the fore. The model of a glass chamber created for this purpose gained virtually worldwide acceptance. The Hans Theo Schreus Award for investigations on the penetration of drugs into the human skin acknowledged this extremely important progress in the pharmacokinetics of topical drugs.

Hans Schaefer's creativity combined with his aesthetic sensitivity and the ability to translate unconventional ideas into technical methods are developed both in his private life and in clinical research. His scientific activities were generously promoted by the Deutsche Forschungsgemeinschaft and the results were published as a monograph on the transcutaneous permeation dynamics. This subject has always been of special interest to him, as shown in his last monograph Skin Barrier, Principles of Percutaneous Absorption, published by Karger in 1996, which was written exclusively for researchers as a convenient desktop reference. In 1973, Schaefer was appointed founding and board member of the European Society for Dermatological Research (ESDR) and from 1985 to 1986 he was president of this society. With regard to phototherapy with psoralens, the most beneficial time for UV radiation after local or oral administration of the photosensitizing substance was determined.
In 1973, with his chapter in Biochemistry and in 1974 as coeditor of Functional Dermatology, he contributed to setting the future course in dermatological research.

In 1978, Hans Schaefer accepted the invitation to teach as visiting professor at the Department of Dermatology of Stanford University in California with main emphasis on the pharmacokinetics of photochemotherapy of psoriasis. The development of a short-term therapy of psoriasis with cignolin, which decreased the disturbing side effects and improved the therapeutic effect, was the first result which yielded crucial impulses to new approaches for local dermatological treatment.

L'Oréal offered to set up a research institute in southern France, invested with every freedom as to the selection of scientific staff and choice of topics. There was general agreement at the Free University of Berlin that this offer was not only a chance for Hans Schaefer's future but also for the development of dermatology. As of May 1979, Schaefer acceded to the position of director of the Centre International de Recherches Dermatologiques (CIRD), an institution which was staffed with 140 employees and endowed with extraordinarily extensive technical equipment. Exemplary fundamental research in dermatology then started of the CIRD with international researchers from the fields of anatomy, physiology and pharmacology. The symposia held on the respective focal points were milestones in the development of fundamental research but also in the development of new therapeutic approaches, e.g. new retinoids. The application of molecular aspects in dermatology also included cosmetics.

After serving as director and advisor to the research management of L'Oréal in Paris, he was appointed vice-chairman (1994) and then chairman (1999) of the Gordon Conference in San Francisco. 
Now, in 2000, I am sure that Hans Schaefer will not mind it if I conclude with an abbreviated version of his homepage as it were from his own curriculum vitae:

'My experience in research and research management related to skin pharmacology and physiology is based on a diversified career: basic work in dermato-pharmacology in pharmaceutical industry; research and management in one of the largest dermatological clinics in Europe with focus on aspects of risk/ benefit relations; creation of an industry funded research centre dedicated to innovative compounds and finally advisory function in respect to long-term orientations of the field of cosmetics at large.'

As an ardent yachtsman, Hans Schaefer will presumably not change the course of his life after returning to Berlin. The sails have been replaced by an impressive motorboat, and I suspect he will now make future decisions in the cabin of his boat and will then put them into action within the sphere of Berlin's dermatological universities as an invited lecturer in physiology and skin pharmacology at the Department of the Charité Hospital of the Humboldt University in Berlin. The name of his boat 'Hanulla' (= Hans and Ulla, his wife) symbolically ensures the continuation of the hitherto so successful family Cooperation in Germany, the USA and France.

Dear Hans, my wish for you is that you will be able to enjoy more creative pauses as a member of 32 highly regarded professional organisations and institutions and I am certain that your creativity will continue to have much in store for us in the future.

Günter Stüttgen, Berlin 